\section{editorial}

\section{Denise P. Carvalho}

Professor Adjunto IV, Laboratório de Fisiologia Endócrina, Instituto de Biofisica Carlos Chagas Filho, Universidade Federal do Rio de Janeiro, Rio de Janeiro, RJ.

\title{
TSH de Alto Peso Molecular ou "Macro TSH": Importância do Diagnóstico
}

O ACHADO OCASIONAL DE VALORES negativos de anticorpos anti-receptor de TSH no soro de pacientes com doença de Basedow-Graves levou à descoberta da presença de anticorpos anti-TSH nestes indivíduos (1). Entretanto, a prevalência de anticorpos anti-TSH no soro de portadores de doença de Graves é baixa e estes anticorpos aparentemente não estão envolvidos com a fisiopatologia desta doença, como chegou a ser sugerido na década de 80 (2). Além da descrição de anticorpos anti-TSH no soro de pacientes com Graves, proteínas capazes de inibir a ligação do TSH às células tireóideas também foram detectadas no soro de indivíduos normais (3). Essas moléculas foram caracterizadas como imunoglobulinas (Ig) anti-TSH, as quais reconheciam TSH bovino, suíno ou humano. O epítopo principal, em alguns casos, parece estar relacionado à subunidade alfa do TSH, havendo possibilidade de reação cruzada desses anticorpos com outros hormônios glicoprotéicos adeno-hipofisários, como LH e FSH (4).

Uma das principais funções do sistema imune corresponde à produção de anticorpos, sendo os linfócitos B as células responsáveis pela produção dessas moléculas fundamentais para a defesa do organismo. Há mais de um século o conceito de discriminação entre o "próprio" e o "nãopróprio" pelo sistema imune foi introduzido por Ehrlich (apud ref 5). Segundo esse conceito, as células do sistema imune que são capazes de reconhecer as estruturas que fazem parte do próprio organismo deveriam ser destruídas ou ter a sua função silenciada. Portanto, admitia-se que a produção de auto-anticorpos (anticorpos contra proteínas do próprio organismo) seria secundária à desregulação do sistema imune, o que levaria ao desenvolvimento de doenças. Entretanto, a análise imunoquímica dos anticorpos presentes no soro em condições normais demonstrou a presença de auto-anticorpos da classe das imunoglobulinas $\mathrm{G}$ ( $\mathrm{IgG}$ ) em indivíduos saudáveis, o que corresponderia ao chamado repertório de anticorpos naturais (5). A descoberta dos anticorpos naturais foi de extrema relevância para o avanço do conhecimento sobre o funcionamento dos linfócitos B e culminou com o uso cada vez maior desses anticorpos (imunoglobulinas endovenosas - IVIg) para o tratamento de doenças auto-imunes (5). Na atualidade, há várias questões em aberto sobre a regulação da produção de anticorpos naturais, pois conhecemos ainda muito pouco sobre o sistema imune, sua interação com outros sistemas e o controle da produção de anticorpos contra proteínas que fazem parte do próprio organismo.

Os anticorpos naturais são menos específicos e têm menor afinidade pelo antígeno do que os anticorpos produzidos após imunização ativa (5). Há estudos demonstrando que os anticorpos naturais podem corresponder a cerca de $50 \%$ dos anticorpos presentes no soro de indivíduos normais, sendo a maior parte polireativa, ou seja, capaz de reconhecer mais de um antígeno (5). Essa menor especificidade dos anticorpos naturais seria uma das possíveis explicações para a observação de que os anticorpos anti-TSH poderiam reconhecer TSH bovino e suíno, além de outros antígenos, como outros hormônios glicoprotéicos, pelo menos em alguns casos. 
No artigo de Vieira e cols. (6) estão exemplificados dois casos de TSH sérico elevado secundário à associação da molécula de TSH a proteínas do soro. Num dos casos há ligação do TSH à IgG e no outro ainda não se conhece a identidade da proteína ligadora. Um dos indivíduos estava sendo submetido à investigação para retardo de crescimento e o outro era tratado há 2 anos com L-T4 após diagnóstico de hipotireoidismo, que foi feito muito provavelmente com base no TSH sérico elevado. Nenhum dos indivíduos apresentava presença de anticorpos anti-tireoperoxidase, anti-tireoglobulina ou anti-receptor de TSH, alterações no T4 livre ou sinais e sintomas de hipotireoidismo que justificassem o aumento de TSH. É importante salientar, portanto, que não havia justificativa para a instituição do tratamento substitutivo com L-T4 no indivíduo que vem sendo tratado há dois anos. A prova terapêutica foi importante, entretanto, para levantar a suspeita da presença de auto-anticorpos anti-TSH nesse indivíduo, pois apesar do T4 livre aumentar com a terapia substitutiva, não houve diminuição do TSH sérico. A descoberta de que os dois indivíduos descritos no artigo de Vieira e cols (6) são portadores de TSH de alto peso molecular ("macro TSH") somente ocorreu porque eles se submeteram à dosagem de TSH sérico. Entretanto, ao solicitarmos um exame complementar jamais devemos esquecer a correlação clínico-laboratorial tão bem discutida no estudo de Vieira e cols. (6).

Os avanços nos testes diagnósticos correspondem a uma das maiores inovações médicas das últimas décadas. Com a proliferação de testes diagnósticos, entretanto, a interpretação clínica e as decisões se tornaram mais complexas. O principal objetivo ao solicitarmos um exame complementar é o de confirmar determinada suspeita clínica. O rastreamento de doenças da tireóide é muito importante, principalmente em mulheres após 35-40 anos de idade, devido ao aumento da prevalência de doenças tireóideas a partir desta faixa etária. Além disto, não podemos esquecer do rastreamento de hipotireoidismo congênito, que é fundamental para evitar retardo mental ou alterações psico-motoras graves nos indivíduos afetados. Entretanto, a instituição da terapia substitutiva deve ser sempre bem justificada. Com relação ao diagnóstico de hipotireoidismo congênito baseado na dosagem de TSH, há casos descritos na literatura, de hipertireotropinemia transitória em neonatos secundária à passagem de anticorpos anti-TSH maternos (7). Assim, nos casos de hipertireotropinemia neonatal, talvez seja importante avaliar a presença de anticorpos anti-TSH maternos, evitando que a terapia substitutiva seja inadequadamente iniciada.
Recentemente, um elegante estudo demonstrou que a macroprolactina é biologicamente inativa (8). Há dados sugerindo que o TSH ligado a anticorpos também seja incapaz de se ligar às células tireóideas, o que corrobora os achados clínicos de Vieira e cols. (6), pois os pacientes não têm sinais e sintomas de hipertireoidismo ou bócio, apesar de apresentarem TSH elevado. Por outro lado, também não há características clínicas de hipotireoidismo, ou seja, uma fração do TSH sérico deve ser biologicamente ativa o que é fundamental para manter a função tireóidea normal. No momento, não há dados acerca da meia vida do TSH nesses indivíduos ou se a produção desses auto-anticorpos seria variável ao longo da vida. Talvez alguns exames complementares fossem interessantes para o melhor entendimento da fisiopatologia relacionada à presença de anticorpos anti-TSH. Ou seja, o artigo de Vieira e cols (6) levanta uma série de dúvidas que poderão gerar estudos futuros interessantes no campo da tireoidologia. Várias questões nos ocorrem neste momento, dentre as quais: qual a prevalência de anticorpos anti-TSH na população normal? Como estariam os níveis séricos de LH e FSH nesses indivíduos, uma vez que há descrição de anticorpos anti-cadeia alfa de hormônios glicoprotéicos?

Por último, levantarei uma questão palpitante que está relacionada ao hipotireoidismo sub-clínico, pois dependendo da técnica utilizada para a dosagem de TSH sérico, os valores encontrados nos pacientes com anticorpos anti-TSH poderiam estar dentro da faixa encontrada no hipotireoidismo sub-clínico. Outra questão relaciona-se à quantidade de anticorpos anti-TSH circulante em diferentes indivíduos, o que poderia causar maior ou menor aumento do TSH sérico. No momento, não temos ainda dados sobre a prevalência dos anticorpos anti-TSH que nos permitam discutir melhor o seu possível papel no diagnóstico do "hipotireoidismo sub-clínico", principalmente naqueles pacientes que têm anticorpos anti-tireoperoxidase ou anti-tireoglobulina negativos. Esses pacientes teriam anticorpo anti-NIS? Ou será que teriam diferentes quantidades de anticorpo antiTSH no soro? Talvez a prevalência de anticorpos antiTSH seja maior do que supomos, assim como foi descrito após a descoberta da macroprolactina.

\section{REFERÊNCIAS}

1. Akamizu $\mathrm{T}$, Ishii $\mathrm{H}$, Mori $\mathrm{T}$, Ishihara $\mathrm{T}$, Ikekubo $\mathrm{K}$, Imura $\mathrm{H}$. Abnormal thyrotropin-binding immunoglobulins in two patients with Graves'disease. J Clin Endocrinol Metab 1984; $59: 240-5$ 
2. Ochi $Y$, Nagamune T, Nakajima $Y$, Ishida $M$, Kajita $Y$, Hachiya T, et al. Anti-TSH antibodies in Graves' disease and their failure to interact with TSH receptor antibodies. Acta Endocrinol (Copenh) 1989; 120:773-7.

3. Beall GN, Chopra IJ, Solomon DH, Kruger SR. Serum protein inhibition of thyrotropin binding to human thyroid tissue. J Clin Endocrinol Metab 1978;47:967-73.

4. Ochi Y, Hamazu M, Kajita Y, Nagata A. Demonstration of anti-TSH antibody in TSH binding inhibitory immunoglobulin-positive sera of patients with Graves' disease. Clin Endocrinol (Oxf) 2002;56:405-12.

5. Lemieux R, Bazin R. Autoantibody-induced formation of immune complexes in normal human serum. Curr Pharm Des 2006; 12:173-9.

6. Vieira JGH, Maciel RMB, Hauache OM, Nishida SK, Boelter DMG, Pinheiro MFMC. Valores inesperadamente elevados de TSH: presenca de isoformas de alto peso molecular ("macro TSH") deve ser investigada. Arq Bras Endocrinol Metab 2006;50:445-49.
7. Tamaki H, Takeoka K, Nishi I, Shindoh Y, Tsukada Y, Amino N. Novel thyrotropin (TSH)-TSH antibody complex in a healthy woman and her neonates. Thyroid 1995:5:299-303.

8. Glezer A, Soares CR, Vieira JG, Giannella-Neto D, Ribela MT, Goffin V, et al. Human macroprolactin displays low biological activity via its homologous receptor in a new sensitive bioassay. J Clin Endocrinol Metab 2006; $91: 1048-55$

\section{Endereço para correspondência}

Denise P. Carvalho

Laboratório de Fisiologia Endócrina Instituto de Biofísica Carlos Chagas Filho

Universidade Federal do Rio de Janeiro

CCS, Bloco G - Cidade Universitária

1949-900 Rio de Janeiro - RJ 